\title{
Adrenal Angiomyolipoma with Gastric Outlet Obstruction
}

\author{
${ }^{1}$ Puneet K Srivastava, ${ }^{2}$ Richa Jaiman
}

\begin{abstract}
Angiomyolipoma is neoplasm that derives from perivascular epithelioid cells. It is a rare mesenchymal tumor, usually found in the kidney. Extrarenal angiomyolipoma is uncommon and the most common extrarenal site is the liver. Angiomyolipoma of adrenal is extremely rare, with only four cases reported in the literature. It usually presents as incidentaloma. We report a case of a 45-year-old female patient presenting with pain abdomen, nausea, and repeated episodes of vomiting. Contrast-enhanced computed tomography (CECT) abdomen revealed heterogeneous nonenhancing hypodense fatty lesion in right adrenal gland. Biochemical investigations were negative for functioning adrenal tumor. Right adrenalectomy was done with good outcome. Diagnosis was confirmed by histopathology. The patient recovered without any complications following surgery.
\end{abstract}

Keywords: Adrenal, Angiomyolipoma, Extrarenal, Gastric outlet obstruction.

How to cite this article: Srivastava PK, Jaiman R. Adrenal Angiomyolipoma with Gastric Outlet Obstruction. World J Endoc Surg 2017;9(3):109-110.

\section{Source of support: Nil}

\section{Conflict of interest: None}

\section{INTRODUCTION}

Angiomyolipoma is a benign mesenchymal tumor consisting of varying amounts of mature adipose tissue, smooth muscle, and thick-walled blood vessels. ${ }^{1}$ It arises from perivascular epithelioid cells and is commonly seen in the kidney. The extrarenal sites reported include the bone, colon, heart, lung, parotid gland, skin, spermatic cord, gynecologic organs, and retroperitoneum, with the most common extrarenal site being the liver. ${ }^{2}$ Only four cases of angiomyolipoma of the adrenals have been reported in the world literature. ${ }^{1-3}$

\section{CASE REPORT}

A 45-year-old female presented with off and on epigastric pain with repeated episode of nonbilious vomiting. There

\footnotetext{
${ }^{1}$ Assistant Professor, ${ }^{2}$ Professor

1,2Department of Surgery, Sarojini Naidu Medical College, Agra Uttar Pradesh, India

Corresponding Author: Puneet K Srivastava, Assistant Professor, Department of Surgery, Sarojini Naidu Medical College, Agra, Uttar Pradesh, India, Phone: +919319966783 e-mail: drpunit979@gmail.com
}

was no history of fever, jaundice, or weight loss. Ultrasound abdomen revealed a well-defined $16 \times 14 \mathrm{~cm}$ mass in the right retroperitoneum. The CECT abdomen defined the mass as of right adrenal origin pushing the duodenum anteriorly with inferior vena cava anteromedially. The diagnosis was made as possibility of angiomyolipoma (Fig. 1). Laboratory investigations, serum catecholamine, cortisol, and urinary vanillylmandelic acid were within normal limits. Exploratory laparotomy by right transverse incision revealed a $16 \times 14 \times 10 \mathrm{~cm}$ mass, firm in consistency, quite separate from the right kidney with no definable right adrenal gland. The whole mass was removed without rupture (Figs 2 and 3). Histopathological examination revealed mature fat cells, smooth muscle fibers, and thin-walled blood vessels with peripherally

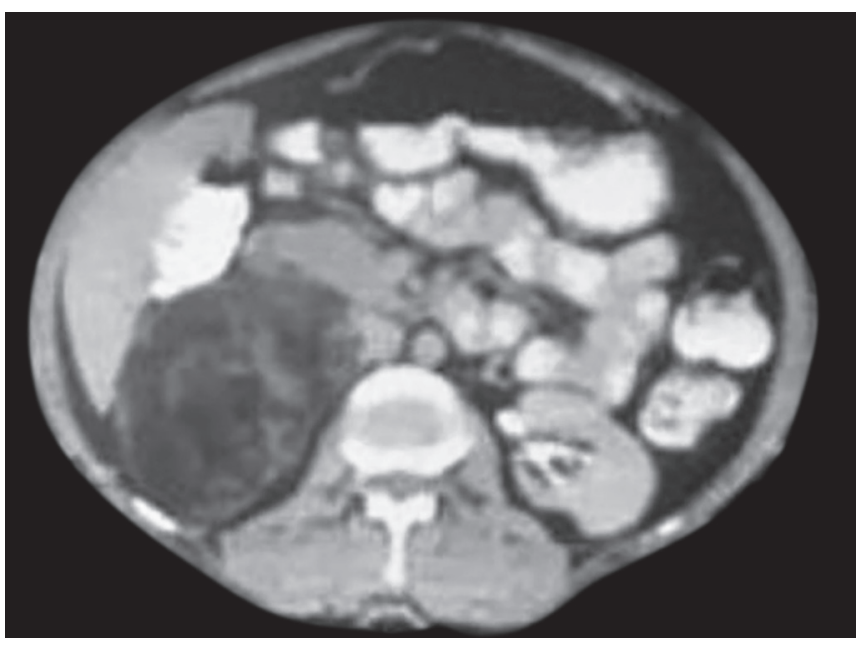

Fig. 1: The CT scan showing large angiomyolipoma, right adrenal

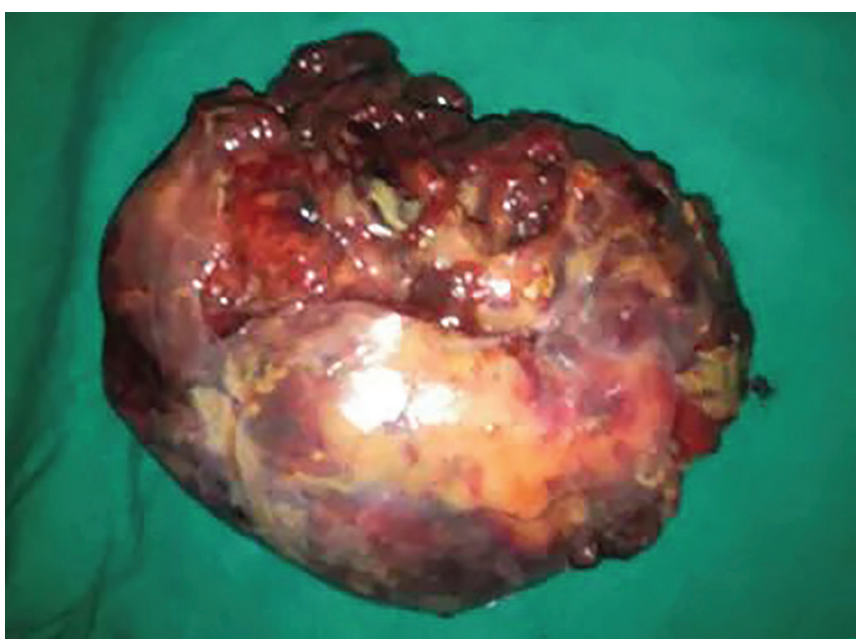

Fig. 2: Excised specimen of angiomyolipoma 


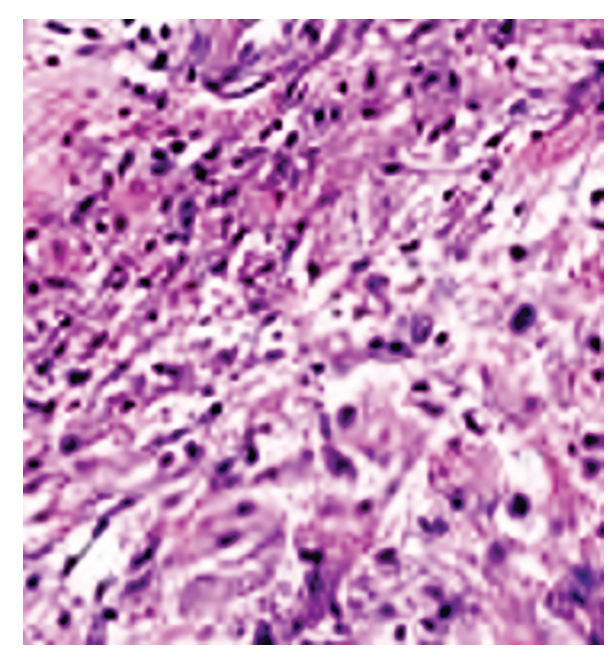

Fig. 3: A mixture of adipose cells with granular cytoplasm and cells that are spindle shaped

compressed adrenal cortical tissue suggestive of angiomyolipoma of adrenal. Patient had an uneventful recovery and was normal at follow-up.

\section{DISCUSSION}

Angiomyolipomas are very rare lesions, often arising in the kidney and are a part of a group of tumors with a diverse appearance known as PEComas (tumors of perivascular epithelioid cell origin). Angiomyolipoma most commonly occurs in the kidney. The next common site is the liver. Extrarenal angiomyolipomas are extremely rare and have been reported in the liver, colon, suprasellar region, small intestine, skin, intranodal, omentum, breast, and adrenal. About half of the angiomyolipomas are associated with tuberous sclerosis and in these cases, they are usually multiple and bilateral. ${ }^{4}$ It has been estimated that approximately $80 \%$ of the severe and complete forms of tuberous sclerosis have angiomyolipoma. ${ }^{5,6}$ On CT scan, the presence of even a small amount of fat suggests the diagnosis of angiomyolipoma. On magnetic resonance imaging, the typical features of the fatty component include bright signal intensity on nonfat suppressed images, with dropout of signal on fat-suppressed images. ${ }^{1}$ Grossly, angiomyolipomas appear well-circumscribed and depending on the relative amount of adipose tissue, they range from a glistening yellow ("fatty") appearance to a more white-tan and firm appearance depending on the relative amount of adipose tissue. $^{2}$ Histology typically shows a variable mixture of mature adipocytes, thick-walled blood vessels, and spindled and epithelioid stromal cells often radiating out from blood vessel walls. Management should be the same as that for any adrenal mass. Assessment of functional status of the tumor should be done, although all the five adrenal angiomyolipomas reported so far were nonfunctional. Surgery is indicated if the patient is symptomatic or the tumor is more than $6 \mathrm{~cm}$ since the risk of malignancy increases with size. ${ }^{7}$ Also, the risk of spontaneous rupture increases with size, owing to the presence of abundant and abnormal elastin and poor vascularity in the tumor. ${ }^{4}$ Laparoscopic adrenalectomy is an option and had been successfully done for a $6 \mathrm{~cm}$ adrenal angiomyolipoma. ${ }^{8}$

Angiomyolipoma of adrenal is extremely rare, with only four cases reported in literature. It usually presents as incidentaloma. We report the case of a 45-year-old female patient presenting with pain abdomen, nausea, and repeated episodes of vomiting. Ultrasonography abdomen showed features of retroperitoneal tumor. The CECT abdomen revealed heterogeneous nonenhancing hypodense fatty lesion in right adrenal gland. Biochemical investigations were negative for functioning adrenal tumor. Right adrenalectomy was done with good outcome. Diagnosis was confirmed by histopathology. The unusual association of adrenal angiomyolipoma with gastric outlet obstruction has not been reported till date.

\section{REFERENCES}

1. Godara R, Vashist MG, Singla SL, Garg P, Sen J, Mathur SK, Gupta A. Adrenal angiomyolipoma: a rare entity. Indian J Urol 2007 Jul-Sep;23(3):319-320.

2. Elsayes KM, Narra VR, Lewis JS Jr, Brown JJ. Magnetic resonance imaging of adrenal angiomyolipoma. J Comput Assist Tomogr 2005 Jan-Feb;29(1):80-82.

3. Lam KY, Lo CY. Adrenal lipomatous tumours: a 30 year clinicopathological experience at a single institution. J Clin Pathol 2001 Sep;54(9):707-712.

4. Eble JN. Angiomyolipoma of the kidney. Semin Diagn Pathol 1998 Feb;15(1):21-40.

5. Bernstein J, Robbins TO, Kissane JM. The renal lesions of tuberous sclerosis. Semin Diagn Pathol 1986 May;3(2):97-105.

6. Martignoni G, Pea M, Rocca PC, Bonetti F. Renal pathology in the tuberous sclerosis complex. Pathology 2003 Dec;35(6): 505-512.

7. Grumbach MM, Biller BM, Braunstein GD, Campbell KK, Carney JA, Godley PA, Harris EL, Lee JK, Oertel YC, Posner MC, et al. Management of the clinically inapparent adrenal mass ("incidentaloma"). Ann Intern Med 2003 Mar;138(5):424-429.

8. Sutter R, Boehler A, Willmann JK. Adrenal angiomyolipoma in lymphangioleiomyomatosis. Eur Radiol 2007 Feb;17(2): 565-566. 